\title{
Hybrid Options for Light-Duty Vehicles
}

\begin{abstract}
The submitted manuscript has been created by the University of Chicago as Operator of Argonne National Laboratory ("Argonne") under Contract No. W-31-109-ENG-38 with the U.S. Department of Energy. The U.S. Government retains for itself, and others acting on its behalf, a paid-up, nonexclusive, irrevocable worldwide license in said article to reproduce, prepare derivative works, distribute copies to the public, and perform publicly and display publicly, by or on behalf of the Government.
\end{abstract}

\section{ABSTRACT}

Hybrid electric vehicles (HEVs) offer great promise in improving fuel economy. In this paper, we analyze why, how, and by how much vehicle hybridization can reduce energy consumption and improve fuel economy. Our analysis focuses on efficiency gains associated solely with vehicle hybridization. We do not consider such other measures as vehicle weight reduction or air- and tire-resistance reduction, because such measures would also benefit conventional technology vehicles. The analysis starts with understanding the energy inefficiencies of light-duty vehicles associated with different operation modes in U.S. and Japanese urban and highway driving cycles, with the corresponding energy-saving potentials. The potential for fuel economy gains due to vehicle hybridization can be estimated almost exclusively on the basis of three elements: the reducibility of engine idling operation, the recoverability of braking energy losses, and the capability of improving engine load profiles to gain efficiency associated with specific HEV configurations and control strategies. Specifically, we evaluate the energy efficiencies and fuel economies of a baseline MY97 Corolla-like conventional vehicle (CV), a hypothetical Corolla-based minimal hybrid vehicle (MHV), and a MY98 Prius-like full hybrid vehicle (FHV). We then estimate energy benefits of both MHVs and FHVs over CVs on a performance-equivalent basis. We conclude that the energy benefits of hybridization vary not only with test cycles, but also with performance requirements. The hybrid benefits are greater for "Corolla (high) performanceequivalent" vehicles than for "Prius (low) performanceequivalent" vehicles. An increasing acceleration requirement would result in larger fuel economy benefits from vehicle hybridization.

\section{INTRODUCTION}

Background. The Partnership for a New Generation of Vehicles (PNGV) has identified hybrid electric vehicle technology as a key component to achieve the supercar goal of 80 miles per gallon. Many car manufacturers have already started or are planning to market commercial HEVs in the next few years. Toyota is the first major car maker to introduce a commercially available hybrid vehicle - the "Prius"- in the Japanese market and will sell it in the U.S. market starting in the year 2000. While the
Feng An, Frank Stodolsky, and Danilo Santini Argonne National Laboratory

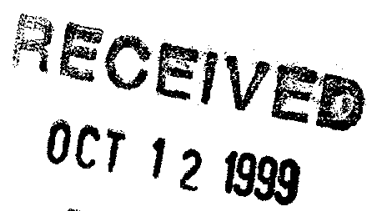

OS T

Prius is considered to be a full hybrid vehicle, other car manufacturers are pushing for a minimal hybrid vehicle or "lowstorage hybrid vehicle" (LSR), such as Honda's VV (just renamed "Insight") and DaimlerChrysler's "Mybrid" [1-3]. HEVs have emerged as serious candidates in the alternative transportation technology market for passenger vehicles.

While a FHV is considered a more radical change from the conventional ICE vehicle (CV), a MHV is considered a more natural evolution from a $\mathrm{CV}$, resulting from a historical trend of increasing vehicle on-board electric power. Historically, the vehicle electric power growth rate is about $6 \%$ from $1920-40$, $2 \%$ from $1940-70$, and $6 \%$ from $1970-90$ [1]. Industry projections indicate this trend will continue, resulting in different levels of vehicle electrification and hybridization, as suggested by Figure 1 .

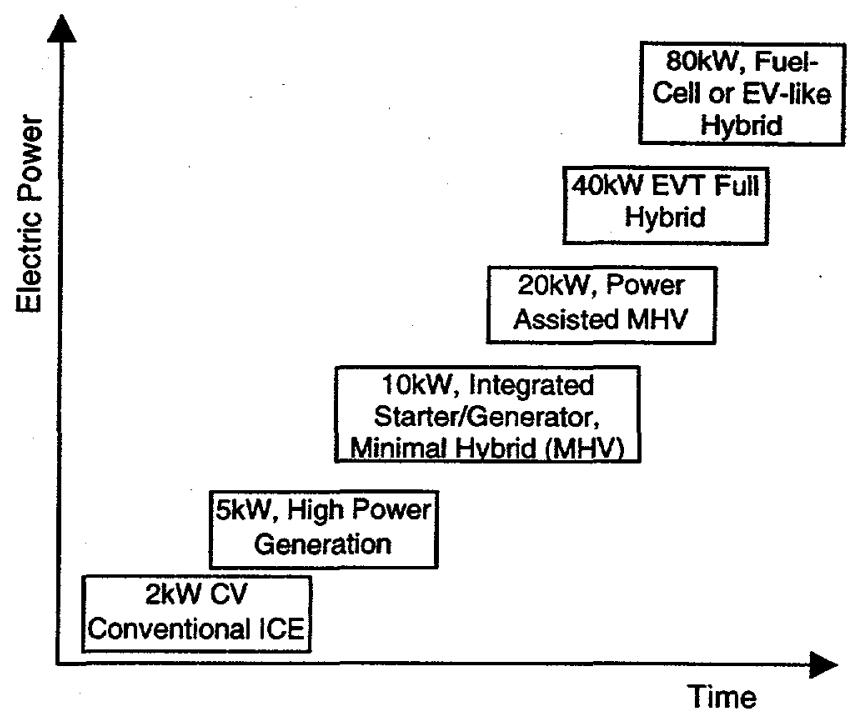

Figure 1. Projected Vehicle On-Board Electric Power Trends

Figure 1 shows that current CVs have an on-board electric power requirement of about $2 \mathrm{~kW}$. This electric power requirement will increase to about $3-5 \mathrm{~kW}$ in the next few years to add such features as heated seats/windows, multimedia, water/oil pumps, power steering, HVAC fan, electromagnetic valves, and heated catalyst. 


\section{DISCLAIMER}

This report was prepared as an account of work sponsored by an agency of the United States Government. Neither the United States Government nor any agency thereof, nor any of their employees, make any warranty, express or implied, or assumes any legal liability or responsibility for the accuracy, completeness, or usefulness of any information, apparatus, product, or process disclosed, or represents that its use would not infringe privately owned rights. Reference herein to any specific commercial product, process, or service by trade name, trademark, manufacturer, or otherwise does not necessarily constitute or imply its endorsement, recommendation, or favoring by the United States Government or any agency thereof. The views and opinions of authors expressed herein do not necessarily state or reflect those of the United States Government or any agency thereof. 


\section{DISCLAIMER}

Portions of this document may be illegible in electronic image products. Images are produced from the best available original document. 
Currently, all major auto manufacturers and suppliers are working on the so-called "integrated starter-generator" system, which will increase on-board electric power to about 10$15 \mathrm{~kW}$ and support such features as fast crank, torque smoothing, engine idle-off and launch assist, and a certain degree of regenerative braking. The Honda VV hybrid vehicle belongs to this category. When electric power increases to 20 $\mathrm{kW}$, the vehicle's internal-combustion engine (ICE) can be further downsized, with such added features as electric HVAC, power assist, fast heating, and limp-home capability. DaimlerChrysler's Mybrid belongs to this category. Vehicles with on-board electric power capability of $10-20 \mathrm{~kW}$ are often called minimal (or mild) hybrid vehicles (MHVs). All major U.S. and European manufacturers are pushing for this concept of hybrid vehicles, along with standardization of a 14/42 voltage electrical system.

When on-board electric power increases beyond $20 \mathrm{~kW}$, as in the Toyota Prius and in proposed fuel-cell hybrid vehicles, it finally reaches the so-called "full hybrid vehicle" (FHV) territory. A FHV with a significantly downsized engine and large electric motor, combined with "electrically variable transmission" (EVT) technologies like those developed by Toyota and Nissan [4-6], will achieve the maximum benefit from vehicle hybridization. But a full hybrid technology may be too costly to the consumer and therefore has high risk of lack of customer acceptance.

This Analysis. In this paper, we first establish baseline CV efficiencies and fuel economies associated with various test cycles. We then analyze fuel economy gains associated with both minimal hybridization and full hybridization of a gasoline baseline vehicle. Specifically, a MY97 Corolla, a hypothetical Corolla-based MHV, and a MY98 Prius-like FHV will be analyzed. The analysis is based on an established vehicle modal energy and emissions model developed by $F$. An and others [7]. A detailed description of the simulation models used for this analysis can be found in references 7-9.

Table 1 lists the basic characteristics of a MY97 Corolla, a Corolla-based MHV, and a MY98 Prius. While the Corolla weighs about $2875 \mathrm{lb}$, the Prius weighs about $3333 \mathrm{lb}$ (about $460 \mathrm{lb}$ more). The pseudo Corolla-based MHV is estimated to weigh about $3100 \mathrm{lb}$, mid-way between the Corolla $\mathrm{CV}$ and Prius FHV.

Table 1 also lists the basic characteristics of the IC engines associated with the CV, MHV, and FHV. Notice that, for the pseudo Corolla-based MHV, a Tercel engine can be used as the on-board ICE. This engine has 1.5 liter displacement, about $20 \%$ downsized from the original Corolla's 1.8 liter engine.

Table 1 also lists the on-board electric power, total maximum power, weight-to-power ratio, and estimated $0-60 \mathrm{mph}$ acceleration time of these vehicles. It clearly shows that, compared with the Corolla CV, the Prius FHV has a much higher weight-to-power ratio (52 vs. 34 ) and a much slower 0 60 time $(14+\mathrm{sec}$ vs. $11 \mathrm{sec})$. Thus, in our final analysis, we will adjust the performance differences and assess both the "Prius (low) performance-equivalent" and "Corolla (high) performance-equivalent" fuel economies of all these vehicles.

\begin{tabular}{l|ccc}
\hline Specificatons & Corolla.CV & $\begin{array}{c}\text { Corolla-based } \\
M H V^{*}\end{array}$ & Prius-FHV \\
\hline Vehicle Specifications & & & \\
Weight (lb) & $2875(1311 \mathrm{~kg})$ & $3100(1409 \mathrm{~kg})$ & $3333(1515 \mathrm{~kg})$ \\
Transmission & $\mathrm{A4}$ & $\mathrm{A4}$ & EVT \\
Cd & 0.3 & 0.3 & 0.3 \\
Frontal Area (m²) & 2.0 & 2.0 & 2.2 \\
Cr_0 & 0.009 & 0.009 & 0.007 \\
\hline Engine Specifications & Corolla engine & Tercel engine & Atkinson engine \\
No. of Cylinders & 4 & 4 & 4 \\
\#. Valves per Cylinder & 4 & 4 & 4 \\
Displacement (liter) & 1.8 & 1.5 & 1.5 \\
Max. thermal efficiency & $35 \%$ & $35 \%$ & $38 \%$ \\
Max. power (hp@rpm) & $115 @ 5600$ & $69 @ 5400$ & $58 @ 4000$ \\
Max.tor. (lb*ft@rpm) & $115 @ 2800$ & $100 @ 4400$ & $75 @ 4000$ \\
\hline Performance & $" H i g h "$ & "High" & "Low" \\
ICE Max. Power (kW) & 85 & 69 & 43 \\
Electric Power (kW) & $1-2^{* *}$ & 15 & 21 \\
Total Max. Power (kW) & 85 & 84 & 64 \\
Wt/Power (lb./kW) & 34 & 37 & 52 \\
0-60 time (sec.) & 11 & 12 & $14+$ \\
\hline
\end{tabular}

* Hypothetical vehicle.

**None is available as motive power.

Table 1. Vehicle/Engine Characteristics of MY97 U.S. Corolla CV, Corolla-based MHV, and MY98 Japanese Prius FHV

Energy Saving Scenarios. Another way to distinguish a CV from a MHV or FHV is based on different energy saving potentials and efficiencies, as described by Table 2. For CVs, energy consumption during engine idling operation and vehicle braking energy are totally wasted. These two kinds of energy losses can be recovered moderately by MHVs and significantly by FHVs. CVs also have very low engine partload efficiency and vehicle transmission efficiency during urban driving cycles. These can also be moderately improved by the MHV and more significantly by the FHV.

\begin{tabular}{l|ccc}
\hline $\begin{array}{l}\text { Energy Savings Scenario for } \\
\text { Urban Driving }\end{array}$ & Conventional & MHV & FHV \\
\hline Idle energy use reducible & $0 \%$ & + & ++ \\
Braking energy recoverable & $0 \%$ & + & ++ \\
$\begin{array}{l}\text { Engine part-load factor or } \\
\text { battery round-trip efficiency }\end{array}$ & Low & + & ++ \\
$\begin{array}{l}\text { Transmission efficiency in } \\
\text { city (mechanical or electric) }\end{array}$ & Low & + & + \\
\hline
\end{tabular}

Table 2. Energy Saving Scenarios for CV, MHV, and FHV

\section{CONVENTIONAL VEHICLE ENERGY CONSUMPTION ANALYSIS}

In this section, the energy and efficiency characteristics of a MY97 Toyota Corolla are analyzed over six different driving cycles. The focus of the analysis is to understand the energy inefficiencies of such a vehicle under different operating conditions, as well as the potential for improvement. 
Six diverse driving cycles are used in the evaluation: EPA's Highway Cycle (HWY), EPA's City Cycle (LA4), CARB's Unified LA 92 Cycle (LA92), the New York City Cycle (NYCC), the US06 Cycle (US06), and the Japanese 10/15 Cycle (Japan). The characteristics of these six driving cycles are summarized in Table 3 . In this table, the Time column represents the duration of these cycles in seconds, $D$ is the length of each cycle in $\mathrm{km}$ (miles in parentheses), $\langle\nu\rangle$ is the average speed in $\mathrm{km} / \mathrm{h}(\mathrm{mph}), v_{\max }$ is the maximum speed in $\mathrm{km} / \mathrm{h}(\mathrm{mph}), a_{\max }$ is the maximum acceleration rate in $\mathrm{m} / \mathrm{s}^{2}$ $(\mathrm{mph} / \mathrm{s})$, and $K_{\max }$ is the maximum specific energy $K$ in $\mathrm{m}^{2} / \mathrm{s}^{3}$ $\left(\mathrm{mph}^{2} / \mathrm{s}\right) . K$, defined as 2*velocity* acceleration rate, is a measure of the change rate of a vehicle's kinetic energy. More detailed analysis of these cycles can be found in references [7, 9]. Table 3 and other tables presenting results by driving cycles are ordered from the slowest to fastest average speed for the cycles.

\begin{tabular}{|c|c|c|c|c|c|c|}
\hline Cycle & $\begin{array}{l}\text { Time, } \\
\text { sec. }\end{array}$ & $\begin{array}{c}\mathbf{D}, \\
\mathbf{k m} \\
\text { (mile) }\end{array}$ & $\begin{array}{l}\langle v\rangle \\
\mathrm{km} / \mathrm{h} \\
(\mathrm{mph})\end{array}$ & $\begin{array}{l}v_{\max }, \\
\mathbf{k m} / \mathbf{h} \\
(\mathrm{mph})\end{array}$ & $\begin{array}{c}\mathrm{a}_{\max }, \\
\mathrm{m} / \mathrm{s}^{2} \\
(\mathrm{mph} / \mathrm{s})\end{array}$ & $\begin{array}{c}\mathrm{K}_{\mathrm{max}} \\
\mathrm{m}^{2} / \mathrm{s}^{3} \\
\left(\mathrm{mph} \mathrm{h}^{2} / \mathrm{s}\right)\end{array}$ \\
\hline NYCC & 599 & $\begin{array}{c}1.9 \\
(1.2)\end{array}$ & $\begin{array}{r}11.4 \\
(7.1) \\
\end{array}$ & $\begin{array}{c}44.6 \\
(27.7)\end{array}$ & $\begin{array}{c}2.7 \\
(6.0)\end{array}$ & $\begin{array}{c}38.8 \\
(194.0)\end{array}$ \\
\hline JAPAN & 631 & $\begin{array}{c}4.2 \\
(2.6)\end{array}$ & $\begin{array}{c}23.8 \\
(14.8) \\
\end{array}$ & $\begin{array}{c}70.0 \\
(43.5) \\
\end{array}$ & $\begin{array}{c}0.79 \\
(1.78)\end{array}$ & $\begin{array}{c}21.5 \\
(107.5)\end{array}$ \\
\hline LA4 & 1372 & $\begin{array}{r}12.0 \\
(7.5)\end{array}$ & $\begin{array}{c}31,4 \\
(19.5)\end{array}$ & $\begin{array}{c}912 \\
(56.7)\end{array}$ & $\begin{array}{c}1.5 \\
(3.3)\end{array}$ & $\begin{array}{c}38.4 \\
(192.0)\end{array}$ \\
\hline LA92 & 1435 & $\begin{array}{r}15.8 \\
(9.9) \\
\end{array}$ & $\begin{array}{c}39.7 \\
(24.7) \\
\end{array}$ & $\begin{array}{l}109.4 \\
(68.0) \\
\end{array}$ & $\begin{array}{c}4.0 \\
(9.0) \\
\end{array}$ & $\begin{array}{c}74.3 \\
(372.0) \\
\end{array}$ \\
\hline $\mathrm{CAFE}^{*}$ & N/A & $\mathbf{N} / \mathbf{A}$ & $\begin{array}{c}52.2 \\
(32.4)\end{array}$ & $\begin{array}{c}96.4 \\
(59.9)\end{array}$ & $\begin{array}{c}1.5 \\
(3.3)\end{array}$ & $\begin{array}{c}38.4 \\
(192.0)\end{array}$ \\
\hline USO6 & 600 & $\begin{array}{r}12.9 \\
(8.0)\end{array}$ & $\begin{array}{c}77.2 \\
(48.0)\end{array}$ & $\begin{array}{l}129.2 \\
(80.3)\end{array}$ & $\begin{array}{c}3.8 \\
(8.5)\end{array}$ & $\begin{array}{c}97.3 \\
(486.7)\end{array}$ \\
\hline HWY & 765 & $\begin{array}{c}16.5 \\
(10.3)\end{array}$ & $\begin{array}{c}77.6 \\
(48.2)\end{array}$ & $\begin{array}{c}96.4 \\
(59.9)\end{array}$ & $\begin{array}{c}1.5 \\
(3.3)\end{array}$ & $\begin{array}{c}31.4 \\
(157.0)\end{array}$ \\
\hline
\end{tabular}

* CAFE represents combined HWY (45\%) and LA4 (55\%) cycles.

Table 3. Characteristics of Six Driving Cycles (plus CAFE)

Figure 2 plots speed traces of the above six driving cycles, excluding the composite CAFE cycle.

\section{Conventional Vehicle Modeling Results}

The simulation results are presented in Table 4, which shows that the Corolla's fuel economy varies significantly from cycle to cycle. The fuel economy of the modeled Corolla ranges from about 15.4 MPG in the NYCC to about $45 \mathrm{MPG}$ in the HWY cycle. Table 4 also shows the EPA test fuel economy results. The HWY and US06 results show that fuel economy at a given average speed (both at about $48 \mathrm{mph}$ ) can vary significantly, depending on the nature of the driving cycle.

\section{Conventional Vehicle Energy Inefficiency Analysis}

To effectively assess the energy benefits of vehicle hybridization, it is important to understand the energy inefficiencies of light-duty vehicles on the basis of the following three areas [10]:
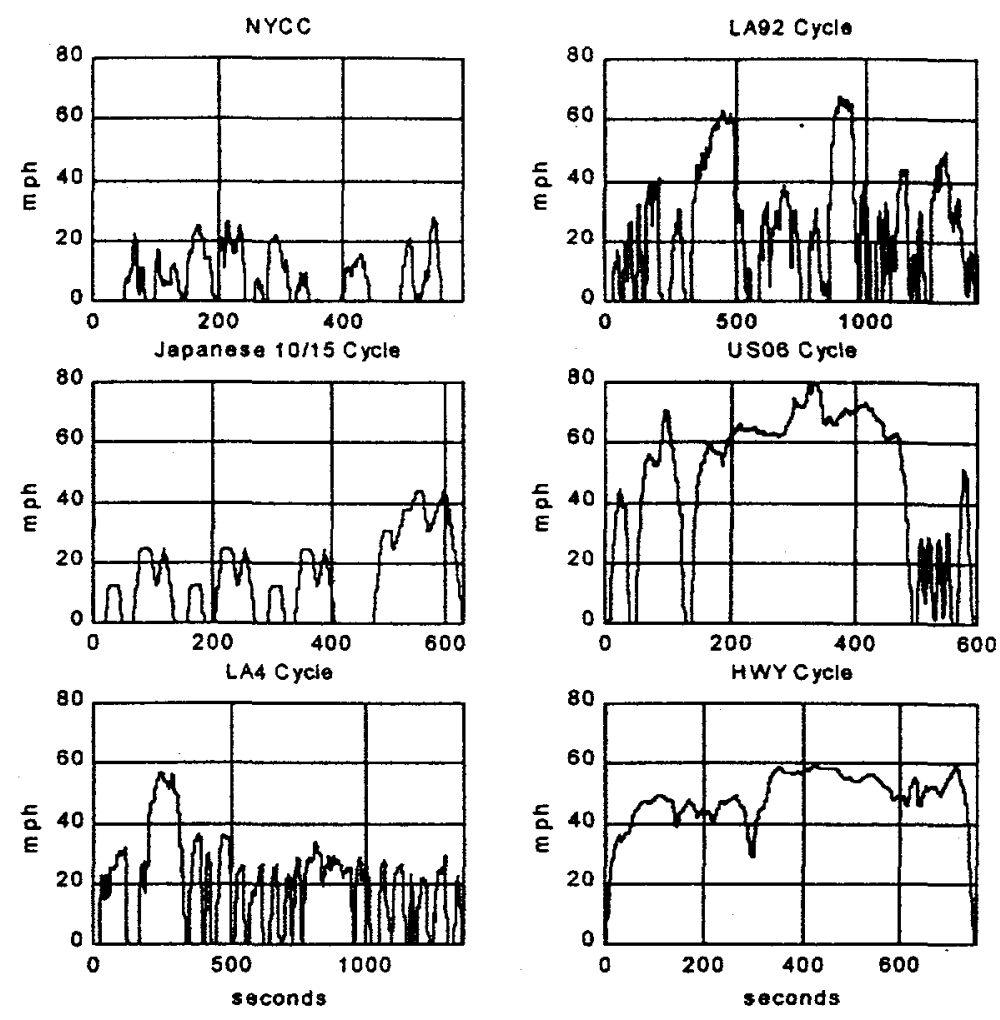

Figure 2. Speed Traces of Six Driving Cycles

\begin{tabular}{c|ccc}
\hline Cycle & MPG (modeled) & MPG $(\mathrm{EPA})$ & $\mathrm{CO}_{2}(\mathrm{~g} / \mathrm{mi})$ \\
\hline NYCC & 15.4 & - & 563.5 \\
JAPAN & 28.0 & - & 310.3 \\
LA4 & 29.4 & 29.9 & 277.8 \\
LA92 & 29.4 & - & 294.4 \\
CAFE & 34.7 & 35.1 & 240.0 \\
US06 & 30.7 & - & 281.0 \\
HWY & 44.8 & 44.7 & 193.9 \\
\hline
\end{tabular}

Table 4. Toyota Corolla Energy and Emission Performance under Different Driving Cycles.

1. Energy loss associated with engine idling operation (when engine power demand $\leq 0$ ).

2. Energy transferred to vehicle brakes (when engine power demand $<0$ ).

3. Energy inefficiency associated with low engine part-load efficiency (when engine power $>0$ ).

Fuel Consumption during Engine Idling Mode. In the engine idling mode, vehicles are stopped or engaged in negativepower driving operation (or braking mode). Table 5 shows the time spent and energy contributions from the modeled Corolla during engine idling mode. The table shows a large variation among these cycles. In the composite CAFE cycle, the engine idling mode contributes about $28 \%$ of the time and $13 \%$ of the fuel to the corresponding total values. For the Japanese 10/15 cycle, the corresponding numbers are $52 \%$ and $28 \%$, respectively. 


\begin{tabular}{c|cc}
\hline Cycle & $\begin{array}{c}\text { Time } \\
(\%)\end{array}$ & $\begin{array}{c}\text { Fuel } \\
(\%)\end{array}$ \\
\hline NYCC & 63.8 & 38.8 \\
JAPAN & 52.3 & 27.6 \\
LA4 & 43.2 & 21.6 \\
LA92 & 45.1 & 15.1 \\
CAFE & 27.9 & 13.0 \\
US06 & 28.5 & 5.0 \\
HWY & 9.3 & 2.5 \\
\hline
\end{tabular}

Table 5. Time and Fuel Contributions of the MY97 Corolla in Engine Idling Mode (\%)

Energy Losses Associated with Vehicle Braking Operation Mode. For a given driving cycle, when the simulated vehicle power demand becomes negative, the vehicle's brake is applied'. The cumulative negative vehicle power represents the total energy lost during vehicle braking, with the exclusion of losses to aerodynamic drag and tire resistance. The cumulative engine positive power represents the total energy demand (or engine work) over a driving cycle by an engine, so the ratio of cumulative negative power over cumulative positive power is a measure of relative braking energy loss, representing the availability of regenerative energy at the vehicle's wheel. Table 6 shows that the relative braking energy loss varies greatly from cycle to cycle. For the CAFE cycle, the braking energy loss is about $20 \%$ of total engine work. For the Japanese $10 / 15$ cycle, the braking energy loss is about $32 \%$ of total engine work.

\begin{tabular}{c|c|c|c}
\hline Cycle & $\begin{array}{c}\text { PositiveWork } \\
(\mathrm{kWh})\end{array}$ & $\begin{array}{c}\text { Negative Work } \\
(\mathrm{kWh})\end{array}$ & $\begin{array}{c}\text { Ratio } \\
(\%)\end{array}$ \\
\hline NYCC & 1.7 & -0.55 & 43.9 \\
JAPAN & 0.4 & -0.19 & 32.1 \\
LA4 & 1.7 & -0.55 & 32.0 \\
LA92 & 2.2 & -0.13 & 37.2 \\
CAFE & 1.9 & -0.4 & 20.3 \\
US06 & 2.9 & -1.09 & 21.1 \\
HWY & 2.2 & -0.13 & 6.1 \\
\hline
\end{tabular}

Table 6. Ratios of Cumulative Negative Power over Cumulative Engine Work (\%)

Vehicle Operating Efficiencies. We have used the following definitions to describe light-duty conventional vehicle operating efficiency $[10,11]$ :

Peak Engine Efficiency, also referred to as "peak brake thermal efficiency," is defined as engine indicated (or thermal) efficiency times engine maximum mechanical efficiency.

Engine Part-Load Efficiency Factor is defined as engine average efficiency over a test cycle divided by the engine peak efficiency. (The engine part-load efficiency defined here does not include transmission efficiency.) Thus, engine part-load efficiency is a measure of the deficiency between the average engine efficiency and the peak engine efficiency.

\footnotetext{
${ }^{1}$ When the engine power demand equals zero, the vehicle is in coastdown driving mode.
}

Vehicle Transmission Efficiency is defined as cumulative power demand at the wheel, divided by cumulative power demand at the engine shaft (or battery terminal for EV or HEV cases). It is a measure of vehicle transmission loss.

Overall Vehicle Efficiency, the overall efficiency from drive wheel to fuel consumption, is the product of the three efficiencies defined above.

Table 7 presents these efficiencies for the MY97 Corolla under different cycles.

\begin{tabular}{|c|c|c|c|c|}
\hline Cycle & $\begin{array}{l}\text { Peak Engine } \\
\text { Efficiency (a) }\end{array}$ & $\begin{array}{c}\text { Part-Load } \\
\text { Engine } \\
\text { Eff. Factor }(b)\end{array}$ & $\begin{array}{l}\text { Avg. Trans. } \\
\text { Efficiency } \\
\text { (c) }\end{array}$ & $\begin{array}{c}\text { Overall } \\
\text { Efficiency } \\
d=a * b * c\end{array}$ \\
\hline NYCC & 35 & 45.1 & 53.6 & 8.5 \\
\hline JAPAN & 35 & 49.0 & 76.0 & 13.0 \\
\hline LA4 & 35 & 56.3 & 78.5 & 15.5 \\
\hline LA92 & 35 & 68.1 & 83.1 & 19.8 \\
\hline CAFE & 35 & 67.3 & 85.5 & 20.2 \\
\hline US06 & 35 & 78.8 & 90.0 & 24.8 \\
\hline HWY & 35 & 80.8 & 94.1 & 26.6 \\
\hline
\end{tabular}

Table 7. Corolla Operating Efficiency under Six Different Cycles

Table 7 shows that the part-load engine efficiency factor varies greatly from cycle to cycle, ranging from as low as $45 \%$ in the NYCC to as high as about $81 \%$ in the HWY cycle. The engine part-load efficiency over the CAFE composite cycle is about $67 \%$. The transmission efficiency also varies greatly from cycle to cycle, ranging from about $54 \%$ in the NYCC to about $94 \%$ in the HWY cycle. The average transmission efficiency over the CAFE composite cycle is about $86 \%$. The variations associated with engine part-load efficiency and transmission efficiency result in even greater variation in overall vehicle efficiency, ranging from below $9 \%$ in the NYCC to over $26 \%$ in the HWY cycle, about a three-fold difference. The overall vehicle efficiency over the CAFE cycle is about $20 \%$ for this particular vehicle.

\section{MINIMAL HYBRID VEHICLE (MHV) ANALYSIS}

This section analyzes the vehicle efficiency gains associated with the so-called "minimal vehicle hybridization." A pseudo Corolla-based vehicle with a Tercel engine, combined with an integrated starter-generator system, is analyzed. Here we are only interested in a "load-following," grid-independent CVlike MHV [8], because we believe such hybrid vehicles offer the best opportunities for fuel economy improvement and are probably more cost-effective in the U.S. [11-12], although high fuel costs in other nations could tip the balance toward FHVs there. The vehicle and engine specifications are given in Table 1. As mentioned before, there are basically three benefits associated with vehicle hybridization: 
1) Engine downsizing and control strategies to improve engine part-load efficiency, ${ }^{2}$

2) Engine idle-off to recover idling energy loss, and

3) Regenerative braking.

The first benefit is expected to be relatively small for minimal hybridization; the engine is only downsized by about $15-20 \%$ and still provides essentially all traction power, the only exception being for very aggressive driving where the battery may provide a power boost. Table 8 shows the simulation model's estimation of engine part-load efficiency gains associated with engine downsizing from an original 1.8-liter Corolla engine to a 1.5 -liter Tercel engine. It shows that the overall efficiency gain is about $3 \%$ over the HWY cycle, $8 \%$ over the LA4 cycle, and 6\% over the composite CAFE cycle. Without including the benefits of idle-off and regenerative braking technologies, the fuel economy has been improved from 44.8 to about $45.5 \mathrm{MPG}$ for the HWY cycle and from 29.4 to 30.6 MPG for the LA4 cycle.

\begin{tabular}{c|ccccccc}
\hline & $\begin{array}{c}\text { Peak } \\
\text { Engine } \\
\text { Efficiency } \\
(\%)\end{array}$ & $\begin{array}{c}\text { Part-Load } \\
\text { Engine } \\
\text { Efficiency } \\
(\%)\end{array}$ & $\begin{array}{c}\text { Avg. } \\
\text { Trans. } \\
\text { Efficiency } \\
(\%)\end{array}$ & $\begin{array}{c}\text { MHV } \\
\text { Overall } \\
\text { Effiency } \\
(\%)\end{array}$ & $\begin{array}{c}\text { Eff. } \\
\text { Gain }\end{array}$ & $\begin{array}{c}\text { New } \\
(\%)\end{array}$ & MPG \\
\hline NYCC & 35.0 & 51.1 & 53.6 & 9.6 & 12.9 & 16.5 \\
JAPAN & 35.0 & 54.8 & 75.9 & 14.6 & 12.3 & 29.7 \\
LA4 & 35.0 & 60.8 & 78.3 & 16.7 & 7.7 & 30.6 \\
LA92 & 35.0 & 71.3 & 82.9 & 20.7 & 4.5 & 29.3 \\
CAFE & 35.0 & 70.9 & 85.4 & 21.5 & 6.4 & 35.9 \\
US06 & 35.0 & 79.5 & 89.9 & 25.0 & 0.8 & 29.9 \\
HWY & 35.0 & 83.3 & 94.0 & 27.4 & 3.0 & 45.5 \\
\hline
\end{tabular}

Table 8. Corolla Operating Efficiency, Efficiency Gain, and New MPG (no idle-off and regen. benefit)

Energy Savings from Regenerative Braking. We have also assessed the availability of regenerative braking energy (at vehicle wheel) as the percentage of total engine work (second column of Table 9); it ranges from about $6 \%$ in the HWY cycle to more than $45 \%$ in the NYCC. But not all of the available braking energy can be recovered. The recoverability of braking energy is basically constrained by the following three factors:

1) Recovering only from front-wheel drive, only about $70 \%$ of total braking energy can be recovered.

2) Battery round-trip charge-discharge efficiency (including motor/converter loss), about $80 \%$ for an optimal system. ${ }^{3}$

3) Constraints due to generator/battery-pack rated power. E.g., if the lesser of a generator's rated power and a

\footnotetext{
${ }^{2}$ For the sake of simplicity in this analysis, for an optimally designed hybrid vehicle, the battery charge-discharge round-trip efficiency is treated as equivalent to engine part-load efficiency factor (both of them can reach beyond $80 \%$ ).

${ }^{3}$ However, we recognize that this efficiency is also variable and affected by the driving cycle as well.
}

battery's peak charging power is only $10 \mathrm{~kW}$, the vehicle as a whole will not be able to recover braking power in excess of $10 \mathrm{~kW}$. We also estimated that, due to the motor/controller power loss, the regenerative braking will not be effective when regenerative power is below 2.5 $\mathrm{kW}$. On this basis, we calculated the fraction of the braking energy between $2.5-10 \mathrm{~kW}$ and $2.5-15 \mathrm{~kW}$ power for the Corolla MHV, respectively, under these six cycles, as shown in the $3^{\text {rd }}$ and $4^{\text {th }}$ columns of Table 9.

\begin{tabular}{c|ccc}
\hline & $\begin{array}{c}\text { Available } \\
\text { Regen. Energy } \\
(\%)\end{array}$ & $\begin{array}{c}\text { Fraction } \\
2.5-10 \mathbf{k W} \\
(\%)\end{array}$ & $\begin{array}{c}\text { Fraction } \\
2.5-15 k \boldsymbol{W} \\
(\%)\end{array}$ \\
\hline NYcle & 45.2 & 69 & 81 \\
JAPAN & 33.1 & 93 & 93 \\
LA4 & 33.0 & 78 & 90 \\
LA92 & 38.3 & 58 & 71 \\
CAFE & 21.0 & 72 & 85 \\
US06 & 21.7 & 48 & 65 \\
HWY & 6.3 & 65 & 79 \\
\hline
\end{tabular}

Table 9. Fractions of the Braking Energy below 10 and $15 \mathrm{~kW}$ for the Corolla MHV under Six Cycles

Table 9 shows that these fractions vary with cycles. This can be illustrated by examining Figure 3, which shows the histogram of braking power for the Prius in the LA4 (upper plot) and Japanese 10/15 (lower plot) cycles. Figure 3 shows that the Japanese $10 / 15$ cycle has a very "narrow" distribution of regenerative power, ranging from $-1 \mathrm{~kW}$ to $-12 \mathrm{~kW}$. While the LA4 cycle has a much "broader" distribution of regenerative power, ranging from extremely low braking powers (near $0 \mathrm{~kW}$ ) to over $-25 \mathrm{~kW}$. The high counts of braking events close to zero power implies that there are many small "fluctuating" deceleration events that cannot be effectively recovered for regenerative braking under the LA4 cycle.
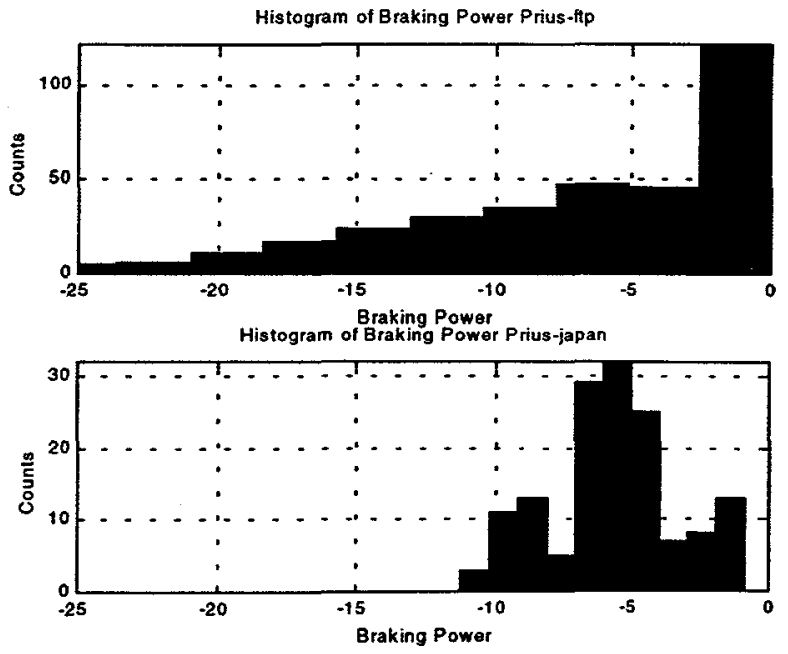

Figure 3. Histogram of Braking Power for the Prius in the LA4 (upper plot) and Japanese 10/15 (lower plot) Cycles. 
Both Table 9 and Figure 3 also imply that, as the on-board electric power increases, the fraction of braking energy that can be recovered increases as well (with the exception of the Japanese cycle beyond $12 \mathrm{~kW}$ braking power.)

Assuming the Corolla MHV has a 10-kW on-board batterycharging capability (which is usually significantly lower than the rated discharge power at high battery state-of-charge, SOC), based on Table 9 , about $72 \%$ of the available braking energy can be utilized for the composite CAFE cycle, and $93 \%$ of it can be utilized for the Japanese 10/15 cycle. Combining these factors with $70 \%$ front-wheel recoverable and $80 \%$ battery-roundtrip efficiency, we come up with a reasonable estimation of braking energy recoverability $[70 \% \times$ $80 \% \times$ (fraction of braking power from 2.5 to $10 \mathrm{~kW}$ )], as shown in the third column of Table 10 .

\begin{tabular}{ccc|cc}
\hline & $\begin{array}{c}\text { Available } \\
\text { Regen. Energy } \\
(\%)\end{array}$ & $\begin{array}{c}\text { Regen. Energy } \\
\text { Recoverable } \\
(\%)\end{array}$ & $\begin{array}{c}\text { Idling } \\
\text { Fuel } \\
(\%)\end{array}$ & $\begin{array}{c}\text { Idle Fuel } \\
\text { Reducible } \\
(\%)\end{array}$ \\
\hline Nycle & 45.2 & 38.6 & 35.7 & 80.0 \\
JAPAN & 33.1 & 52.1 & 25.3 & 80.0 \\
LA4 & 33.0 & 43.7 & 19.6 & 80.0 \\
LA92 & 38.3 & 32.5 & 13.1 & 80.0 \\
CAFE & 21.0 & 40.4 & 11.8 & 80.0 \\
US06 & 21.7 & 26.9 & 4.3 & 80.0 \\
HWY & 6.3 & 36.4 & 2.2 & 80.0 \\
\hline
\end{tabular}

Table 10. Braking Energy Recoverability and Idle Fuel Reducibility of the Corolla MHV

Table 10 shows our estimates that the overall regenerative energy recoverable is about $36 \%$ for the HWY cycle, $44 \%$ for the LA4 cycle, $52 \%$ for the Japanese $10 / 15$ cycle, and $40 \%$ for the composite CAFE cycle. The overall energy saving from regenerative braking is determined on the basis of combining Columns 2 and 3 of Table 10, as shown in the third column of Table 11.

Column 4 of Table 10 also shows the percentage of idling fuel consumption for the pseudo MHV Corolla with a 1.5-liter Tercel engine. For the MHV, an $80 \%$ savings of idle fuel is assumed for all cycles ${ }^{4}$. The overall energy saving from engine idle-off is determined on the basis of combining Columns 4 and 5 of Table 10, as shown in the second column of Table 11 .

Table 11 shows the percentage of fuel savings associated with both engine idle-off and regenerative braking technologies, as well as the final fuel economy of the MHV Corolla and the percentage of fuel economy gains over the baseline Corolla. The combined CAFE fuel economy can be improved to reach 45 MPG for the composite cycle (47.4/43.3 for HWY/City cycles), a gain of about $26 \%$ over the baseline vehicle. The

\footnotetext{
${ }^{4}$ Since a FHV is likely to be driven by an electric motor alone at low load, this makes $100 \%$ reducibility of idle energy loss possible. In contrast, a MHV would almost never be driven by an electric motor alone; in some instances, the on-board engine cannot be shut off instantly during brief deceleration events.
}

fuel economy gains are significantly higher for the NYCC and the Japanese $10 / 15$ cycle.

\begin{tabular}{c|ccc|cc}
\hline \multirow{2}{*}{ Cycle } & \multicolumn{3}{|c|}{ Fuel Saving } & \multicolumn{3}{c}{ Corolla-based MHV } \\
\cline { 2 - 6 } & Idle & Regenerative & Total & New & MPG \\
$(\%)$ & $(\%)$ & $(\%)$ & MPG & Gain (\%) \\
\hline NYCC & 28.6 & 17.0 & 45.5 & $\mathbf{2 9 . 7}$ & 80.3 \\
JAPAN & 20.2 & 16.7 & 37.0 & $\mathbf{4 6 . 7}$ & $\mathbf{5 7 . 3}$ \\
LA4 & 15.7 & 14.0 & 29.7 & $\mathbf{4 3 . 3}$ & $\mathbf{4 1 . 4}$ \\
LA92 & 10.5 & 12.1 & 22.6 & $\mathbf{3 7 . 6}$ & $\mathbf{2 8 . 6}$ \\
CAFE & 9.4 & 8.7 & 18.1 & $\mathbf{4 5 . 0}$ & $\mathbf{2 5 . 5}$ \\
US06 & 3.4 & 5.6 & 9.1 & $\mathbf{3 2 . 9}$ & $\mathbf{1 0 . 2}$ \\
HWY & 1.8 & 2.2 & 4.0 & $\mathbf{4 7 . 4}$ & $\mathbf{4 . 2}$ \\
\hline
\end{tabular}

Table 11. Fuel Saving and MPG Gains Associated with Engine IdleOff and Regenerative Braking

\section{FULL HYBRID VEHICLE (FHV) ANALYSIS: TOYOTA PRIUS - A CASE STUDY}

This section analyzes fuel economy benefits of a full hybrid vehicle, with a MY98 Toyota Prius as a sample vehicle.

Power-Split HEV Simulation Model. The power-split HEV simulation model flowchart is shown in Figure 4 (modeled after the Toyota Prius). This configuration is neither a parallel nor a series configuration. It is closer to the parallel configuration but differs in that a planetary gear system combined with a starter/generator can transfer power between the ICE and electric motor, both of which are coupled to the driveshaft. In this configuration, the ICE provides the primary power, with a power-split device (planetary gear with starter/generator) sending power to both the driveshaft and the electric motor.

The key element for modeling the power-split HEV configuration is to model the planetary-gear/generator device. A detailed description of such a modeling effort can be found in [8].

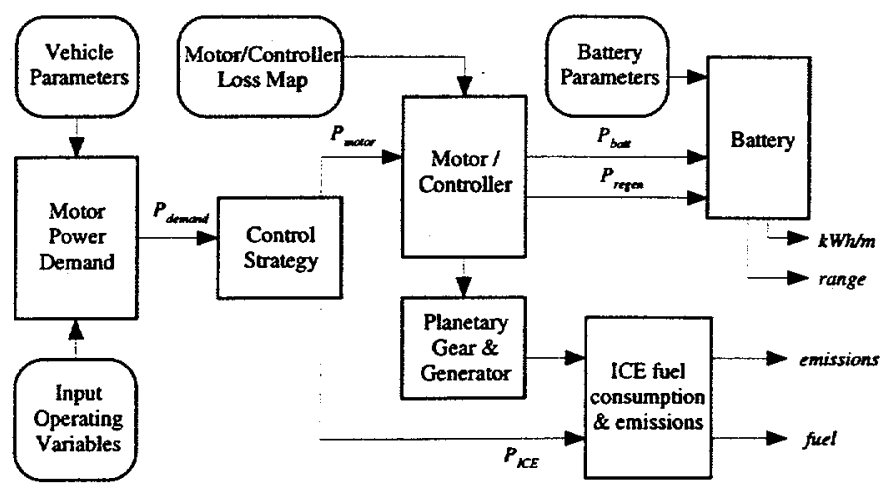

Figure 4. Power-Split HEV Simulation Model Flowchart

Figure 5 shows the simulated Prius engine performance map. This map is generated on the basis of limited knowledge about the Prius engine characteristics and of our analytical engine fuel consumption model. Although the MY98 Prius restricts the engine to be operated only below $4000 \mathrm{rpm}$, we plot the 
simulated engine map over an operational range comparable to that of the base gasoline 1.5-liter engine (i.e., up to $5500 \mathrm{rpm}$ ). Key features about the engine map include the following:

1. Its peak efficiency is approximately $38 \%$ (or $215 \mathrm{~g} / \mathrm{kWh}$ bsfc), compared to $35 \%(235 \mathrm{~g} / \mathrm{kWh}$ bsfc) for the Corolla/Tercel engine.

2. It has no fuel enrichment operation. This is evidenced by the engine performance contour map presented in [4], which shows that there is no closed efficiency island in the map; engine efficiency keeps increasing toward wideopen throttle operation. This can only be achieved by elimination of enriched operation. The half-closed contour lines indicate that engine friction increases at both ends of the engine speed spectrum.

3. The Tercel engine, which also has 1.5-liter displacement, is a very efficient engine, with efficiency islands centered on $2000 \mathrm{rpm}$ in a relatively low engine torque range. In contrast, the simulated Prius engine has a very broad high-efficiency area close to its maximum torque and all the way from 1000 to $4000 \mathrm{rpm}$.

4. In the actual Prius configuration, the engine is confined to an operating range between 1000 and $4000 \mathrm{rpm}$, except during cranking for starts, which are frequent.

The operational strategy for the power-split HEV is a loadfollowing strategy. The on-board engine is turned off and batteries are engaged when power demand is below a motive power level. (We estimate the lower motive power level corresponding to the $30 \%$ efficiency point of the Prius engine, which is approximately $6 \mathrm{~kW}$ of power demand.) When the power demand exceeds the maximum power rating of the engine, the battery is engaged to provide additional power. The battery SOC is always maintained between 40 and $60 \%$ through on-board charging by regenerative braking and the IC engine.

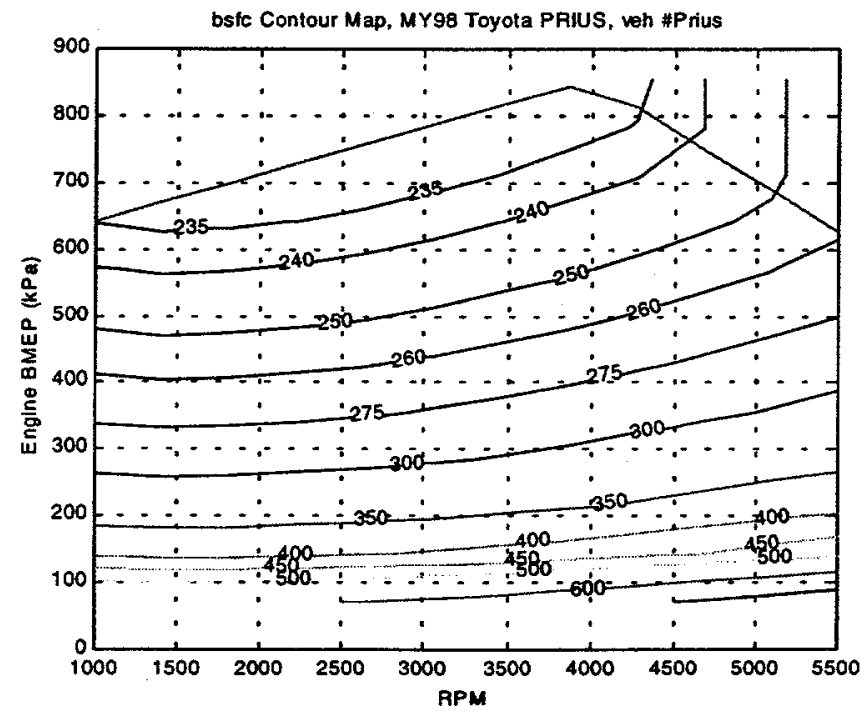

Figure 5. Simulated Prius Engine Performance Map.
Modeling Results. Figure 6 presents the modeled equivalent fuel economy for the Prius under the various test cycles. It shows that the Prius achieves the best fuel economy (63 MPG) under the Japanese $10 / 15$ cycle. Its worst economy is about 35 MPG under the NYCC.

Prius Energy Efficiency Analysis. Since the Prius has an electrically variable transmission (EVT) and Atkinson cycle engine, its engine peak efficiency, engine part-load efficiency, transmission efficiency, and overall vehicle efficiency are all significantly higher than those of both CVs and MHVs, as shown by Table 12. For the composite CAFE cycle, while the CV's overall efficiency is about 20\% (Table 7) and the MHV's overall efficiency is about $22 \%$ (Table 8 ), the Prius FHV's overall efficiency exceeds $29 \%$, as shown in the fifth column of Table 12.

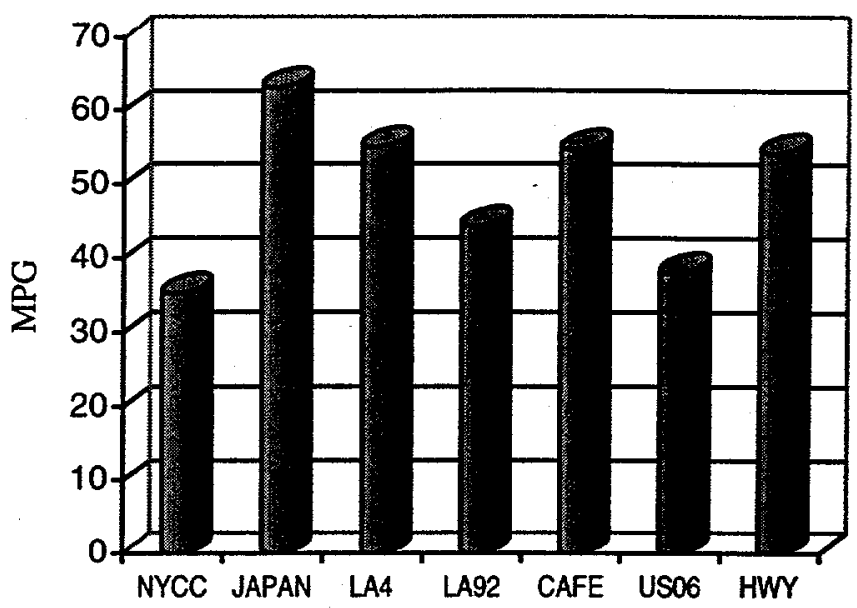

Figure 6. Fuel Economy for Toyota Prius under Driving Cycles.

Since there is a great degree of uncertainty in determining the recoverability of regenerative energy, as a first step, we estimate the Prius's fuel economy without the impact of regenerative braking. The last column of Table 12 shows "intermediate" Prius fuel economies (without the impacts of regenerative braking, but including the impacts of engine idleoff).

\begin{tabular}{c|ccccc}
\hline & $\begin{array}{c}\text { Peak } \\
\text { Engine } \\
\text { Efficiency } \\
\text { Cycle }\end{array}$ & $\begin{array}{c}\text { Part-Load } \\
\text { Engine } \\
\text { Efficiency } \\
(\text { b })\end{array}$ & $\begin{array}{c}\text { Avg. } \\
\text { Trans. } \\
\text { Efficiency } \\
(\text { c })\end{array}$ & $\begin{array}{c}\text { FHV } \\
\text { Overall } \\
\text { Efficiency } \\
(\%)\end{array}$ & $\begin{array}{c}\text { MPG } \\
\text { (no Regen.) }\end{array}$ \\
\hline NYCC & 38.0 & 72.9 & 55.1 & 15.3 & 27.1 \\
JAPAN & 38.0 & 82.0 & 80.2 & 25.0 & 46.8 \\
LA4 & 38.0 & 82.1 & 80.2 & 25.0 & 44.7 \\
LA92 & 38.0 & 84.9 & 85.4 & 27.6 & 36.7 \\
CAFE & 38.0 & 88.0 & 87.7 & 29.3 & 48.6 \\
US06 & 38.0 & 90.5 & 93.2 & 32.1 & 34.7 \\
HWY & 38.0 & 95.2 & 96.9 & 35.1 & 52.4 \\
\hline
\end{tabular}

Table 12. Prius Operating Efficiency under Different Cycles without Regenerative Braking 
Even though the Prius has an electric motor of $30 \mathrm{~kW}$ rated power, its NiMH battery has an energy capacity of $1.8 \mathrm{kWh}$ and power capacity of $21 \mathrm{~kW}$. A typical NiMH battery's charging capacity is about $80 \%$ of its discharging capacity around 50\% SOC [12]; thus, we estimate the Prius battery's peak charging power around $17 \mathrm{~kW}$. On the basis of the same methodology applied in the previous section, we estimate the braking energy available as a percentage of total engine work $\left(2^{\text {nd }}\right.$ column of Table 13 ), a fraction of the braking energy between $2.5 \mathrm{~kW}$ and the Prius battery's maximum charging power of $17 \mathrm{~kW}$ ( $3^{\text {rd }}$ column), overall braking energy recoverability $\left(4^{\text {th }}\right.$ column), total fuel saving due to regenerative braking $\left(5^{\text {th }}\right.$ column), and final fuel economy of the modeled Prius (last column).

\begin{tabular}{c|ccccc}
\hline & $\begin{array}{c}\text { Regen. } \\
\text { Available } \\
(\%)\end{array}$ & $\begin{array}{c}\text { Regen. } \\
(\%)\end{array}$ & $\begin{array}{c}\text { Ruel } \\
\text { Recoverable } \\
(\%)\end{array}$ & $\begin{array}{c}\text { Saving } \\
(\%)\end{array}$ & $\begin{array}{c}\text { New } \\
\text { MPG }\end{array}$ \\
\hline NYcle & 49.0 & 85 & 47.6 & 23.3 & $\mathbf{3 5 . 3}$ \\
JAPAN & 38.1 & 96 & 53.8 & 20.5 & $\mathbf{6 3 . 1}$ \\
LA4 & 37.8 & 89 & 49.8 & 18.8 & $\mathbf{5 5 . 1}$ \\
LA92 & 43.1 & 71 & 39.8 & 17.1 & $\mathbf{4 4 . 3}$ \\
CAFE & 24.3 & 84 & 47.1 & 10.4 & $\mathbf{5 4 . 7}$ \\
US06 & 25.0 & 64 & 35.8 & 9.0 & $\mathbf{3 8 . 1}$ \\
HWY & 7.9 & $\mathbf{7 8}$ & 43.7 & 3.5 & $\mathbf{5 4 . 3}$ \\
\hline
\end{tabular}

Table 13. Fuel Savings Associated with Regenerative Braking and Prius FHV Fuel Economy

The last column of Table 13 shows that the Prius achieves the highest fuel economy under the Japanese 10/15 cycle, primarily due to the high fraction of regenerative power between 2.5 and $17 \mathrm{~kW}(96 \%)$ in the Japanese $10 / 15$ cycle. In contrast, only about $78 \%, 89 \%$, and $84 \%$ of braking power is available between 2.5 and $17 \mathrm{~kW}$ for the HWY, LA4, and composite CAFE cycles, respectively. Thus, fuel saving from regenerative braking is about $21 \%$ for the Japanese $10 / 15$ cycle, about twice that for the composite CAFE cycle (10\%). To improve the Prius's fuel economy performance in the U.S. market, one possibility is to improve the braking energy recoverability under the HWY and LA4 cycles. We estimate that the peak braking power for the Prius under the HWY cycle is about $35 \mathrm{~kW}$, while under the LA4 cycle it is about $26 \mathrm{~kW}$. So the Prius for the U.S. market, with a larger battery pack with peak-power charging capacity $>30 \mathrm{~kW}$, would have better fuel economy.

The above results compare favorably with the EPA's dynamometer test results [13] and analysis based on another simulation model - the "Advisor" simulation model [14].

\section{PERFORMANCE EQUIVALENT COMPARISONS}

We have so far assessed a baseline CV's energy efficiency and fuel economy, as well as the efficiency and fuel economy gains associated with a minimal hybrid vehicle and a full hybrid vehicle. The energy-saving scenarios associated with these two cases can be summarized by Table 14 (under the composite CAFE cycle). Our analysis is based on estimates that the idling fuel use reducibility is about $80 \%$ for MHVs and $100 \%$ for FHVs. The braking energy recoverability during the combined CAFE cycle is about $40 \%$ for MHVs and $47 \%$ for FHVs. The engine efficiency gain from the FHVs (about $45 \%$ ) is much higher than that from MHVs (about $6 \%$ ). We also estimate that the Prius has about $30 \%$ of its driving miles under pure electric operation during the combined CAFE cycle $[5,8]$, while both CVs and MHVs have essentially zero pure electric operation. The only physical downside associated with vehicle hybridization is the weight increase. Based on the weight difference between the MY97 Corolla and the MY98 Prius, vehicle weight increases about $8 \%$ (or about $100 \mathrm{~kg}$ ) for the MHV, and about $16 \%$ (or $200 \mathrm{~kg}$ ) for the FHV. The increased vehicle weight is mostly associated with the added weight of battery pack, traction motor, generator and electronic controller, which are partially offset by the reduced weight of the downsized IC engine.

\begin{tabular}{|c|c|c|c|}
\hline $\begin{array}{l}\text { Energy Savings Scenario } \\
\text { (under CAFE cycle) }\end{array}$ & $\begin{array}{l}\text { Baseline } \\
\text { CV }\end{array}$ & $\begin{array}{c}\text { Minimal } \\
\text { Hybrid }\end{array}$ & $\begin{array}{c}\text { Full } \\
\text { Hybrid } \\
\end{array}$ \\
\hline Idle energy use reducible & $0 \%$ & $80 \%$ & $100 \%$ \\
\hline Braking energy recoverable & $0 \%$ & $\sim 40 \%$ & $\sim 47 \%$ \\
\hline Engine efficiency gain & $0 \%$ & $-6 \%$ & $-45 \%^{5}$ \\
\hline Pure EV operation ${ }^{6}$ & $0 \%$ & $0 \%$ & $30 \%$ \\
\hline Weight increase & 0 & $8 \%$ & $16 \%$ \\
\hline
\end{tabular}

Table 14 - Energy Savings Scenario for Hybrid Vehicles

Table 15 presents the overall vehicle efficiencies for the CV Corolla, MHV Corolla, and FHV Prius. Columns 2-4 represent efficiencies when regenerative braking and engine idle-off effects are not included, and columns 5-6 represent overall vehicle efficiencies including the impacts of regenerative braking and engine idle-off. Table 15 shows that, when the effects of regenerative braking and engine idle-off are included, the overall vehicle efficiency can exceed $30 \%$ for both the Japanese $10 / 15(30.3 \%)$ and the composite CAFE $(31.7 \%)$ cycles.

\begin{tabular}{c|ccccc}
\hline & \multicolumn{5}{|c}{ Overall Eff. (\%) } \\
\cline { 2 - 6 } & Exclude Regen. \& Idle-Off & Include Regen. \& Idle-Off \\
Cycle & CV & MHV & FHV & MHV & FHV \\
JAPAN & 13.0 & 14.6 & 25.0 & 20.9 & 30.3 \\
LA4 & 15.5 & 16.7 & 25.0 & 21.0 & 28.7 \\
CAFE & 20.2 & 21.5 & 29.3 & 25.3 & 31.7 \\
HWY & 26.6 & 27.4 & 35.1 & 29.1 & 35.4 \\
\hline
\end{tabular}

Table 15. Overall Vehicle Efficiencies for CV Corolla, MHV Corolla, and FHV Prius, with and without Regen. and Idle-Off.

Figure 7 shows the overall vehicle efficiencies for these three vehicles under the HWY, LA4, Japan, and CAFE composite cycles. Table 16 summarizes the fuel economy for these three vehicles. Please keep in mind that, compared to the Corolla

\footnotetext{
${ }^{5}$ Based on Table 7, a CV's overall efficiency is about $20.2 \%$.Table 12 shows that a FHV's overall efficiency can reach $29.3 \%$, an improvement of $45 \%$.

${ }^{6} \mathrm{Here}$, Pure EV operation is measured as a percentage of total vehicle driving miles.
} 
$\mathrm{CV}$, the Prius FHV has a much higher weight-to-power ratio (52 to 34$)$ and a much slower $0-60$ time $(14+\mathrm{sec}$ vs. $11 \mathrm{sec})$. This raises the question of the validity of direct comparisons of these vehicles.

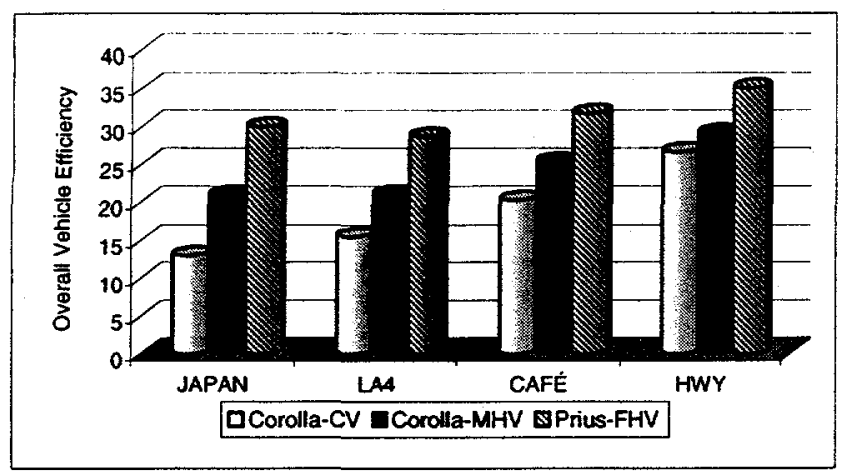

Figure 7. Overall Vehicle Efficiencies for CV, MHV, and FHV under Japan, LA4, CAFE, and HWY cycles.

\begin{tabular}{c|ccc}
\hline \multirow{2}{*}{ Cycle } & \multicolumn{3}{|c}{ Efficiency, $M P G$} \\
\cline { 2 - 4 } & Corolla $C V$ & Coralla $M H V$ & Prius $F H V$ \\
\cline { 2 - 4 } & 11 sec $^{2}$ & 12 sec & $14+$ sec \\
\hline JAPAN & 28.0 & 46.7 & 63.1 \\
LA4 & 29.4 & 43.3 & 55.1 \\
CAFE & 34.7 & 45.0 & 54.7 \\
HWY & 44.8 & 47.4 & 54.3 \\
\hline
\end{tabular}

${ }^{2} 0-60$ time.

Table 16. Summary of Vehicle Fuel Economy and Performance

In the next two sections, we address the "performance equivalent" comparisons. There are two ways to adjust 0-60 performance for these vehicles: (1) adjust CV and MHV performance to match the Prius level (0-60 time in $14 \mathrm{sec})$; and (2) adjust MHV and FHV performance to match the Corolla's level $(0-60$ time in $11 \mathrm{sec})$.

\section{"Prius (Low) Performance Equivalent" Comparisons}

In this section, we approximately adjust both the Corolla CV's and the MHV's acceleration performance to match the Prius's level $(0-60 \text { time in } 14 \mathrm{sec})^{7}$. Due to the unusually low acceleration performance for a U.S. car, this is also a low performance case.

Both the Corolla CV's and the MHV's engines need to be significantly downsized to match the weight-to-power ratio of the Prius. In Table 17, the Corolla CV's IC engine is downsized by $35 \%$, to 1.2 liters, with maximum power of 55 $\mathrm{kW}$. The Corolla MHV's IC engine is downsized by $47 \%$, to 1.0 liters and $45 \mathrm{~kW}$ peak power. As a result of the engine downsizing, the fuel economy of both the "slow" Corolla CV and the "slow" Corolla MHV are significantly improved. The CAFE fuel economy of the Corolla CV is increased from 34.7 MPG in the baseline (or "fast") case to 40.3 MPG in the "slow

\footnotetext{
${ }^{7}$ For the sake of simplicity in the analysis, we only adjust weight-topower ratio. We neglect mass change effects from changes in engine size, as well as the options of changing electronic component sizes.
}

case." The CAFE fuel economy of the Corolla MHV increases from 45.0 MPG ("fast case") to 48.8 MPG ("slow case").

\begin{tabular}{l|ccc}
\hline \multicolumn{1}{c|}{ Parameter } & Corolla CV & Corolla MHV & Prius FHV \\
\hline Vehicle Weight (lb) & 2875 & 3100 & 3333 \\
Displacement (liter) & 1.2 & 1.0 & 1.5 \\
Engine downsizing & $35 \%$ & $47 \%$ & $0 \%$ \\
ICE Max Power (kW) & 55 & 45 & 43 \\
Electric Power (kW) & $1-2$ & 15 & 21 \\
Total Max. Power (kW) & 55 & 60 & 64 \\
Wt/Power (lb/kW) & 52 & 52 & 52 \\
0-60 time (sec) & -14 & -14 & $14+$ \\
\hline & \multicolumn{3}{|c}{ MPG } \\
\multicolumn{1}{c|}{ Cycle } & Slow CV & Slow MHC & Slow FHV \\
\hline JAPAN & 34.4 & 52.2 & 61.7 \\
LA4 & 34.8 & 47.6 & 49.7 \\
CAFE & 40.3 & 48.8 & 49.4 \\
HWY & 49.8 & 50.5 & 51.5 \\
\hline
\end{tabular}

Table 17. Prius (Low) Performance-Equivalent MPG for the CV, MHV, and FHV

Table 18 shows the relative improvement in fuel economy of "Slow" MHV and "Slow" FHV over their "Slow" CV counterpart. The relative MPG improvements from MHV to $\mathrm{CV}$ range from $1 \%$ in the HWY cycle to $52 \%$ in the Japanese $10 / 15$ cycle. The relative MPG improvements from FHV to $\mathrm{CV}$ range from $3 \%$ in the HWY cycle to $79 \%$ in the Japanese $10 / 15$ cycle. Thus, the incremental MPG improvement from MHV to FHV is relatively small in the U.S. cycles - only about $2 \%$ in the HWY cycle, $6 \%$ in the LA4 cycle, and $2 \%$ in the CAFE cycle. The energy benefits of both MHVs and FHVs are larger for more congested, slow-average-speed driving cycles, such as the Japanese 10/15 and the LA4 cycles.

\begin{tabular}{c|ccc}
\hline & \multicolumn{3}{|c}{ MPG Gain (\%) } \\
\cline { 2 - 4 } Cycle & MHV vs. CV & FHV vs. CV & FHV - MHV \\
JAPAN & 52 & 79 & 27 \\
LA4 & 37 & 43 & 6 \\
CAFE & 21 & 23 & 2 \\
HWY & 1 & 3 & 2 \\
\hline
\end{tabular}

Table 18. Fuel Economy Gains of the "Slow" MHV and "Slow" FHV over their "Slow" CV Counterpart

\section{"Corolla (High) Performance-Equivalent" Comparisons}

In this section, we adjust both the Corolla MHV's and the Prius FHV's acceleration performance to match the baseline Corolla CV's level $(0-60$ time in $11 \mathrm{sec})$. Due to the high acceleration level, this is also a high performance case.

\footnotetext{
${ }^{8}$ To make the comparison more fair, we have also further adjusted the fuel economy level of the Prius, where an Atkinson cycle engine is used. Since the Atkinson engine is more efficient than the Corolla engine, and the fuel economy gain associated with using Atkinson engine should not be credted to vehicle hybridization, the Prius FHV's fuel economy is slightly lowered.
} 
In this case. both the MHV's and FHV's IC engines are adjusted to match the weight to power ratio of the baseline Corolla's.' In this analysis, all engines are adjusted based on the baseline Corolla engine (no Atkinson engine for the FHV). Table 19 shows that the MHV's IC engine is slightly adjusted, to 1.6 liter and $76 \mathrm{~kW}$. The FHV's IC engine is sized at 1.5 liter and $70 \mathrm{~kW}$. As a result of the engine resizing, the fuel economy of both the "fast" MHV and the "fast" FHV are reduced - the MHV's CAFE fuel economy is slightly reduced, from 45.0 MPG in the baseline case to 44.0 MPG in the "fast case." The FHV's CAFE fuel economy is reduced from 54.7 MPG in the "slow case" to 49.0 MPG in the "fast case."

\begin{tabular}{|c|c|c|c|}
\hline Parameter & Corolla CV & Corolla $M H V$ & Corolla FHV \\
\hline Vehicle Weight (lb) & 2875 & 3100 & 3400 \\
\hline Displacement (liter) & 1.8 & 1.6 & 1.5 \\
\hline ICE Max Power (kW) & 85 & 76 & 70 \\
\hline Electric Power (kW) & $1-2$ & 15 & 30 \\
\hline Total Max. Power (kW) & 85 & 91 & 100 \\
\hline Wt/Power $(l b / k W)$ & 34 & 34 & 34 \\
\hline $0-60$ time $(\mathrm{sec})$ & 11 & 11 & $11+$ \\
\hline & \multicolumn{3}{|c|}{$M P G$} \\
\hline Cycle & Fast CV & Fast $M H C$ & Fast FHV \\
\hline JAPAN & 28.0 & 45.8 & 56.4 \\
\hline LA4 & 29.4 & 42.6 & 51.1 \\
\hline CAFE & 34.7 & 44.0 & 49.0 \\
\hline HWY & 44.8 & 45.9 & 46.6 \\
\hline
\end{tabular}

Table 19. Corolla (High) Performance-Equivalent MPGs of the CV, MHV, and FHV

Table 20 shows the estimated relative improvement in fuel economy of the "Fast" MHV and "Fast" FHV over their "Fast" CV counterpart. The relative MPG improvements from MHV to CV range from $2 \%$ in the HWY cycle to $64 \%$ in the Japanese $10 / 15$ cycle. The relative MPG improvements from FHV to CV range from $4 \%$ in the HWY cycle to over $100 \%$ in the Japanese 10/15 cycle. Thus, the incremental MPG improvement from the MHV to FHV is much larger than that for the previous "slow performance" case - about $2 \%$ in the HWY cycle, $29 \%$ in the LA4 cycle, $37 \%$ in the Japanese $10 / 15$ cycle, and $14 \%$ in the CAFE cycle. The energy benefits of both MHVs and FHVs are larger for more congested, slowaverage-speed driving cycles, such as the Japanese 10/15 and the LA4 cycles.

\begin{tabular}{c|ccc}
\hline \multirow{2}{*}{ Cycle } & \multicolumn{3}{|c}{ MPG Gain (\%) } \\
\cline { 2 - 4 } JAPAN & MHV vs. CV & FHV vs. CV & FHV - MHV \\
LA4 & $64 \%$ & $101 \%$ & $37 \%$ \\
CAFE & $45 \%$ & $74 \%$ & $29 \%$ \\
HWY & $27 \%$ & $41 \%$ & $14 \%$ \\
\hline
\end{tabular}

Table 20. Fuel Economy Gains of the "Fast" MHV and "Fast" FHV over their "Fast" CV Counterpart

\section{CONCLUSIONS}

This paper assesses the fuel economy benefits of minimal hybrid vehicles (MHVs) and full hybrid vehicles (FHVs). Our conclusions are as follows:

- Both MHVs and FHVs can significantly improve fuel economy under relatively slow-speed urban driving cycles.

- The hybrid benefits are larger for high-performance vehicles than for low-performance vehicles. In other words, an increasing acceleration requirement will result in higher fuel economy benefits from hybridization

- The incremental fuel economy benefits from MHVs to FHVs are estimated to be minimal for a "low performance" vehicle under the U.S. CAFE cycle, but they are significant for "high-performance" vehicles.

- For a low-performance vehicle, over the CAFE cycle, the simulated minimal vehicle hybridization improved fuel economy by $21 \%$, and the full vehicle hybridization improved fuel economy by $23 \%$.

- For a high-performance vehicle, over the CAFE cycle, the simulated minimal vehicle hybridization improved fuel economy by $27 \%$, and a full vehicle hybridization improved fuel economy by $41 \%$.

- The patterns of the gains estimated here are thought to be representative. Those for the FHVs are consistent with test reports in Reference 5.

- Fuel economy improvement is substantial for all cases simply by reducing vehicle power-to-weight ratio. This is primarily a result of the engine's operating closer to its peak efficiency over the drive cycle.

The quantitative results are summarized by Table 21 .

\begin{tabular}{c|ccc}
\hline \multirow{2}{*}{ Cycle } & \multicolumn{3}{|c}{ MPG Gain (\%) } \\
\cline { 2 - 4 } Low-Performance & MHV vs. CV & FHV vs. CV & FHV - MHV \\
JAPAN & & & \\
CAFE & $52 \%$ & $79 \%$ & $27 \%$ \\
High-Performance & $21 \%$ & $23 \%$ & $2 \%$ \\
JAPAN & $64 \%$ & $101 \%$ & $37 \%$ \\
CAFE & $27 \%$ & $41 \%$ & $14 \%$ \\
\hline
\end{tabular}

Table 21. Fuel Economy Gains of the MHV and FHV over their CV Counterpart, under Both "Low" and "High" Performance Cases

\section{ACKNOWLEDGMENTS}

Funding for refinement of the vehicle simulation model developed by F. An et al. has been provided by Dr. James J. Eberhardt, Director, Office of Heavy Vehicle Technologies, U.S. Department of Energy, primarily for purposes of analysis 
of hybridization of medium-duty trucks. In this paper, that model has been extended to the case of light-duty vehicles, with extensions and interpretation of the model results by the authors. Funding for preparation of this paper by the Planning and Assessment function of DOE's Office of Transportation Technologies (OTT), managed by Dr. Philip Patterson, is gratefully acknowledged. This paper is authored by a contractor of the U.S. Government under contract No. W-31109-ENG-38. Accordingly, the U.S. Government retains a nonexclusive, royalty-free license to publish or reproduce the published form of this contribution, or allow others to do so, for government purposes.

\section{REFERENCES}

1. Moore, B. (1999), Advanced Energy Systems, Presented at the SAE Topical Technology Workshop on Hybrid Electric Vehicles: Here and Now (TOPTEC), SAE International, Warrendale, $\mathrm{Pa}$.

2. Rovera, G., and D. Mesaiti (1999), The General Purpose Hybrid Vehicles, Presented at the SAE Topical Technology Workshop on Hybrid Electric Vehicles: Here and Now (TOPTEC), SAE International, Warrendale, $\mathrm{Pa}$.

3. Brigham, D. (1999), The Ford Hybrid Vehicle Program Development Status, Presented at the SAE Topical Technology Workshop on Hybrid Electric Vehicles: Here and Now (TOPTEC), SAE International, Warrendale, $\mathrm{Pa}$.

4. Toyota Hybrid System. Toyota Press Information'97, 1997.

5. Hermance, D. (1999), Toyota Hybrid System, Presented at the SAE Topical Technology Workshop on Hybrid Electric Vehicles: Here and Now (TOPTEC), SAE International, Warrendale, $\mathrm{Pa}$.

6. Matsuo, 1. (1999), High Performance Characteristics of Nissan Hybrid System Combined with CVT, Presented at the SAE Topical Technology Workshop on Hybrid Electric Vehicles: Here and Now (TOPTEC), SAE International, Warrendale, $\mathrm{Pa}$.

7. An, F., M. Barth, M. Ross, and J. Norbeck. (1997), The Development of a Comprehensive Modal Emissions Model: Operating Under Hot-Stabilized Conditions. Transportation Research Board Record Series 1587:5262, Washington, D.C.

8. An, F., and M. Barth (1998), Critical Issues in Quantifying Hybrid Electric Vehicle Emissions and Fuel Consumption. Society of Automotive Engineers (SAE) Technical Paper 981902.

9. An, F., M. Barth, and G. Scora (1997), Impacts of Diverse Driving Cycles on Electric and Hybrid Electric Vehicle Performance. In: SAE Special Publication (SP-1284) on Electric/Hybrid Vehicles: Alternative Powerplants, Energy Management, and Battery Technology. SAE Technical Paper 972646.
10. An, F., F. Stodolsky, and J. Eberhardt (1999), Fuel and Emission Impacts of Heavy Hybrid Vehicles. $32^{\text {nd }}$ ISATA Conference Proceeding, Vienna, Austria, 99CPE015, pp. 193-202.

11. Stodolsky, F., et al. (1999), Total Fuel Cycle Impacts of Advanced Vehicles. SAE Technical Paper 1999-01-0322.

12. Corrigan, D., et al. (1997), Ovonic Nickel-Metal Hydride HEV Batteries Practical for Commercialization Now, EVS 14, Orlando, Fla.

13. Santini, D., J. Anderson, J. He, S. Plotkin, A. Vyas, and D. Bharathan (1999), Gasoline-Fueled Hybrid vs. Conventional Vehicle Emisisons and Fuel Economy, AWMA, 99-185.

14. Hellman, K.H., M.R. Peralta, and G.K. Piotrowski (1998), Evaluation of a Toyota Prius Hybrid System (THS), U.S. Environmental Protection Agency Report EPA 420-R-98006, Ann Arbor, Mich. 